\title{
Statins inhibit matrix metalloproteinase release from human lung fibroblasts
}

\author{
K. Kamio*, X.D. Liu*, H. Sugiura\#, S. Togo*, S. Kawasaki*, X. Wang*, Y. Ahn*, \\ C. Hogaboam ${ }^{\oplus}$ and S.I. Rennard*
}

ABSTRACT: Pleiotropic effects of statins have been reported to include inhibition of matrix metalloproteinase (MMP) release from macrophages and endothelial cells. We evaluated whether statins would inhibit MMP release from human lung fibroblasts, which play a major role in remodelling processes.

Monolayer and three-dimensional (3D) collagen gel cultures of fibroblasts were used. Cytokines (tumour necrosis factor- $\alpha$ and interleukin-1 $\alpha$ ) were used to induce MMP release and mRNA expression. Collagen degradation induced by cytokines and neutrophil elastase (NE) was evaluated by quantifying hydroxyproline. Atorvastatin inhibited MMP-1 and -3 release and mRNA expression in both culture systems. Similar results were obtained with simvastatin and fluvastatin.

In 3D cultures where cytokines also stimulated MMP-9 release, atorvastatin also inhibited MMP-9 release. In 3D cultures, cytokines together with NE induced collagen degradation, which was also inhibited by atorvastatin. The effect of atorvastatin was reversed by mevalonate and geranylgeranyl-pyrophosphate but not by farnesyl-pyrophosphate.

The current data suggest that statins may modulate remodelling processes mediated by fibroblasts by inhibiting MMP release.

KEYWORDS: Collagen, degradation, fibroblasts, matrix metalloproteinases, statins

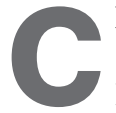
hronic obstructive pulmonary disease (COPD) is expected to become the third leading cause of death worldwide by the year 2020 [1]. The defining feature of COPD is loss of expiratory airflow that can result from at least two important structural alterations in the lungs, emphysema with its destruction of alveolar wall and loss of lung elastic recoil, and peribronchial fibrosis, which narrows airways. At present, therapy can partially alleviate symptoms, but has relatively little impact on the progressive structural alterations that compromise lung function [2]. Novel therapeutic strategies that have the potential to alter lung structure, therefore, are of interest as possible approaches to alter the long-term natural history of COPD. One type of therapy that is attracting interest for its potential in COPD is the use of statins, which have been associated with reduced acute events and mortality [3-5], as well as with reduced decline in lung function in retrospective database studies [6].

Statins are a class of cholesterol-lowering drugs that inhibit 3-hydroxy-3-methylglutaryl coenzyme A (HMG-CoA). Recently, pleiotropic effects of statins have been reported, including anti-inflammatory and antioxidant effects [7, 8], as well as the inhibition of matrix metalloproteinase (MMP) release from vascular cells and macrophages [9-11]. One potential mechanism for statin efficacy in COPD could be effects on inflammatory cells. Such effects could be a mechanism that could alter both acute events and long-term progression. An alternate mechanism, which could be either independent or interactive, is the effect of statins on MMPs. Through these effects, statins could directly modify lung extracellular matrix (ECM) and, thereby, could modify the alterations in lung structure that compromise lung function.

The MMPs are a large family of proteolytic enzymes [12] that are produced by both inflammatory cells and structural cells in the lung including alveolar epithelial cells and fibroblasts [13]. Fibroblasts are believed to be major cells responsible for maintenance and repair of ECM [14]. This is accomplished by the production and assembly of ECM macromolecules, by the release of growth factors for other cells and by the release of proteolytic enzymes, particularly MMPs.
AFFILIATIONS

*Pulmonary and Critical Care Medicine, University of Nebraska Medical Center, Omaha, NE,

"Immunology Program, Dept of Pathology, University of Michigan Medical School, Ann Arbor, MI, USA. \#Third Dept of Internal Medicine, Wakayama Medical University, Wakayama, Japan.

CORRESPONDENCE

S.I. Rennard

University of Nebraska Medical Center 985910 Nebraska Medical Center Omaha NE 68198-5910 USA E-mail: srennard@unmc.edu

Received Oct 122007 Accepted after revision: Sept 042009 First published online: Sept 242009 
This allows fibroblasts to modulate both ECM production and destruction, as well as the response of other cells.

The current study was designed to determine if statins could modulate MMP release by human lung fibroblasts. To investigate this, we utilised two types of lung fibroblasts, the widely used human fetal lung fibroblast strain (HFL-1) [15], which allows our results to be compared with those of other investigations that have used identical or similar strains and, in addition, fibroblasts from normally appearing adult lung tissue that was removed during surgery. We have, moreover, used three statins, atorvastatin, fluvastatin and simvastatin, to assure that the effects were not specific for a single agent. In addition, to determine if the effect of statins could modulate ECM degradation in addition to MMP release and to determine if the results obtained in the conventionally used monolayer culture would be observed in other culture conditions, the effect of atorvastatin was evaluated using three-dimensional (3D) collagen gels in which collagen degradation was induced by cytokines and neutrophil elastase (NE). Finally, the signalling pathway by which atorvastatin exerts its effect on MMP release was investigated in both culture systems.

\section{MATERIALS AND METHODS \\ Materials}

Native type I collagen (rat tail tendon collagen) was extracted from rat tail tendons by a previously published method [16, 17]. Commercially available reagents were obtained as follows: Dulbecco's modified Eagle's medium (DMEM) and fetal calf serum (FCS) were from Invitrogen Life Technologies (Grand Island, NY, USA); human NE was from Elastin Products Company, Inc. (Owensville, MO, USA); recombinant human MMP-1 and -3 Western blotting standards, recombinant human tumour necrosis factor (TNF)- $\alpha$ and interleukin (IL)- $1 \alpha$ and monoclonal anti-human pro/active MMP-1 (Clone 36665) and MMP-3 (Clone 10D6) antibodies were from R\&D Systems, Inc. (Minneapolis, MN, USA); horseradish peroxidase (HRP)conjugated goat anti-mouse IgG was from Rockland (Gilbertsville, PA, USA); fluvastatin and simvastatin were from Calbiochem (San Diego, CA, USA); mevalonate, farnesyl pyrophosphate (FPP), geranylgeranyl pyrophosphate (GGPP), chloramine-T, $p$-dimethylaminobenzaldehyde and 3-(4,5dimethylthiazolyl-2)-2,5- diphenyltetrazoliumbromide (MTT) were from Sigma (St. Louis, MO, USA).

Atorvastatin was a kind gift from Pfizer Inc. (New York, NY, USA) and was dissolved in methanol to a stock solution of $2.5 \mathrm{mM}$.

\section{Cell culture}

HFL-1 (lung, diploid, human) was obtained from the American Type Culture Collection (ATCC; \#CCL-153; Rockville, MD, USA). HT1080 cells (connective tissue fibrosarcoma, diploid, human) were also purchased from ATCC (\#CCL-121). HLFs were isolated from alveolar lung tissue removed at surgery for suspected malignancy that appeared to be free of cancer under a protocol approved by the Human Studies Committee of the University of Michigan (Ann Arbor, MI, USA). The cells were cultured on 100-mm tissue culture dishes (Falcon; Becton-Dickinson Labware, Lincoln Park, NJ, USA) with DMEM supplemented with $10 \% \mathrm{FCS}, 100 \mu \mathrm{g} \cdot \mathrm{mL}^{-1}$ penicillin, $250 \mu \mathrm{g} \cdot \mathrm{mL}^{-1}$ streptomycin sulfate (penicillin-streptomycin; Invitrogen), and $2.5 \mu \mathrm{g} \cdot \mathrm{mL}^{-1}$ amphotericin B (Geneva Pharmaceuticals, Inc., Dayton, NJ, USA). Cells were cultured at $37^{\circ} \mathrm{C}$ in a humidified atmosphere of $5 \% \mathrm{CO}_{2}$ and passaged every 3 to 5 days at a 1:4 ratio. In all experiments, HFL- 1 cells between the 14th and 18th passage were used. For HLF, passages between the seventh and 11th were used. HT1080 cell culture media were used as a positive control for gelatine zymography.

To evaluate the release of MMP in monolayer culture, fibroblasts were cultured in DMEM with $10 \%$ FCS in $60-\mathrm{mm}$ dishes (Falcon) at $0.5 \times 10^{6}$ cells for $24 \mathrm{~h}$. The medium was then changed to serum-free (SF)-DMEM. After $24 \mathrm{~h}$, cells were washed with phosphate-buffered saline (PBS) once and treated with statins for $1 \mathrm{~h}$ before stimulation with cytokines (TNF- $\alpha$ $5 \mathrm{ng} \cdot \mathrm{mL}^{-1}$ and IL-1ß $2 \mathrm{ng} \cdot \mathrm{mL}^{-1}$ ) in SF-DMEM. After 24-h incubation, the media were harvested for gelatine zymography and Western blot analysis.

\section{Collagen gel culture}

Collagen gel cultures were conducted according to the previously published methods [17] with a cell density of $3 \times 10^{5}$ fibroblasts $\cdot \mathrm{mL}^{-1}$ gel. The gels were incubated in SFDMEM either with or without designated reagents at $37^{\circ} \mathrm{C}$ and $5 \% \mathrm{CO}_{2}$ for 3 days.

\section{Hydroxyproline assay}

Hydroxyproline, which is directly proportional to type I collagen content, was measured by spectrophotometry according to the previously published methods [18]. Briefly, the collagen gels were solubilised by heating in $0.1 \mathrm{M} \mathrm{HCl}(50 \mu \mathrm{L} /$ 3 gels). Samples $(20 \mu \mathrm{L})$ were mixed with $30 \mu \mathrm{L} 3.3 \mathrm{M} \mathrm{NaOH}$ and autoclaved at $120^{\circ} \mathrm{C}$ for $20 \mathrm{~min}$. After oxidisation with $0.056 \mathrm{M}$ chloramine- $\mathrm{T}$ for $20 \mathrm{~min}$, samples were reacted with Ehrlich's reagent at $65^{\circ} \mathrm{C}$ for $20 \mathrm{~min}$. The absorbance was measured at $540 \mathrm{~nm}$ with BenchMark Microplate Reader and Microplate Manager III software (Bio-Rad, Hercules, CA, USA).

\section{Western blot analysis of metalloproteinase}

To assess the release of MMP-1 and -3, Western blot analysis was performed according to the previously published method $[19,20]$. Briefly, the supernatants (4 mL per condition) from monolayer and 3D collagen gel cultures were precipitated with $50 \%$ (vol/vol) cold ethanol and re-suspended in $50 \mu \mathrm{L}$ doubledistilled $\mathrm{H}_{2} \mathrm{O}$. Because secreted MMPs were assessed, no internal standard to allow for variable dilution was used. Rather, a constant volume, $35 \mu \mathrm{L}$ of each sample was subjected to $10 \%$ sodium dodecyl sulfate (SDS)-polyacrylamide gel elecrophoresis (PAGE) under nonreducing conditions and then proteins were transferred to polyvinyl difluoride membranes (Bio-Rad). This then allowed comparison of the intensity of the final bands in a manner similar to immunoassay [21, 22]. After blocking with 5\% nonfat milk, blots were incubated overnight at $4{ }^{\circ} \mathrm{C}$ with primary antibodies $\left(1 \mu \mathrm{g} \cdot \mathrm{mL}^{-1}\right.$ mouse anti-human MMP-1 or MMP-3 monoclonal antibody). Target proteins were detected using HRP-conjugated goat antimouse immunogloblin $G$ in conjunction with an enhanced chemiluminescence detection system (Amersham Biosciences UK Limited, Little Chalfont, UK) using a Typhoon Scanner (Amersham Biosciences). Band intensity was quantified using 
ImageJ software version 1.34 s (National Institute of Health; $\mathrm{NIH}$, USA).

\section{Gelatine zymography}

Supernatant media from monolayer and 3D collagen gel cultures (500 $\mu \mathrm{L}$ per culture condition) were concentrated 10fold by precipitation with cold ethanol and re-suspended in $50 \mu \mathrm{L}$ double-distilled $\mathrm{H}_{2} \mathrm{O}$. Gelatine zymography was performed by a modification of previously published procedures $[20,23,24]$. Briefly, $25 \mu \mathrm{L}$ of each sample were separated in $10 \%$ SDS-PAGE containing $0.1 \%$ gelatine (Invitrogen, Carlsbad, CA, USA) under nonreducing conditions. After electrophoresis, the gels were soaked in $2.5 \%$ Triton-X 100 and incubated in metalloproteinase activation buffer containing $\mathrm{CaCl}_{2}$ and $\mathrm{ZnCl}_{2}$ for $16 \mathrm{~h}$ at $37^{\circ} \mathrm{C}$. The gels were stained with $0.4 \%$ Coomassie blue (Bio-Rad) and rapidly destained with destaining buffer (30\% methanol, 10\% acetic acid). The gels were dried between cellophane sheets (Amersham, Piscataway, NJ, USA). Zones of proteolysis appeared as clear bands against a blue background and were scanned by Gel Doc 2000 (Bio-Rad). Band intensity was quantified using ImageJ software.

\section{RNA preparation and complementary DNA synthesis}

To determine whether changes in MMP mRNA levels were present, quantitative real-time PCR was performed. HFL-1 fibroblasts were cultured in $60-\mathrm{mm}$ dishes at $1.5 \times 10^{6}$ cells for $24 \mathrm{~h}$. Cells were then washed by PBS twice and treated with statins for $1 \mathrm{~h}$ before the stimulation by cytokines (TNF- $\alpha$ $5 \mathrm{ng} \cdot \mathrm{mL}^{-1}$ and IL-1 $\beta 2 \mathrm{ng} \cdot \mathrm{mL}^{-1}$ ) in SF-DMEM for $6 \mathrm{~h}$. Total RNA was isolated by a single-step guanidinium-thiocyanate-phenolchloroform extraction procedure designed by CHOMCYNSKI and SACCHI [25], and the total amount of RNA was quantified spectrophotometrically (Shimadzu Scientific Instruments, Inc., Columbia, MD, USA). $1 \mu \mathrm{g}$ of total RNA was transcribed according to the previously published methods [20, 24].

\section{Quantitative real-time PCR}

Gene expression was measured with the use of an ABI Prism 7500 Sequence Detection System (Applied Biosystems) by a slight modification of previously published methods [20, 26]. The same primers and probes for MMP-1, -3 and -9 were used as described by FANG et al. [20]. rRNA was simultaneously tested using TaqMan Ribosomal RNA Control Reagents (Applied Biosystems).

\section{Cell viability assay}

Cell viability was evaluated by MTT assay using previously described methods [27]. Cells were treated with various concentrations of reagents used in this study with MTT solution at a final concentration of $1 \mathrm{mg} \cdot \mathrm{mL}^{-1}$ for $6 \mathrm{~h}$ at $37^{\circ} \mathrm{C}$. After incubation, dimethyl sulfoxide was added into each well. The absorbance of each sample at $540 \mathrm{~nm}$ was determined by BenchMark Microplate Reader (Bio-Rad).

\section{Statistical analysis}

Data are expressed as mean \pm SEM. Each experiment was repeated at least three times. The number of replicates is specified in each figure. Experiments with multiple comparisons were evaluated by one-way ANOVA followed by post hoc analysis by pairwise comparisons of values with Tukey's test to adjust for multiple comparisons. Probability p-values $<0.05$ were considered significant.

\section{RESULTS}

\section{Effect of statins on MMP release in monolayer culture}

HFL-1 cells

To test if statins inhibit the release of MMPs in HFL-1, we first investigated three separate statins, not only to demonstrate the reproducibility of our findings, but to be certain that any effects observed were not specific for a single compound. To accomplish this, cells were cultured in $60-\mathrm{mm}$ dishes and treated with atorvastatin $(2.5 \mu \mathrm{M})$, fluvastatin $(1.0 \mu \mathrm{M})$ or simvastatin $(0.5 \mu \mathrm{M})$ with and without stimulation by cytokines (TNF- $\alpha 5 \mathrm{ng} \cdot \mathrm{mL}^{-1}$ and IL-1 $\beta 2 \mathrm{ng} \cdot \mathrm{mL}^{-1}$ ) for $24 \mathrm{~h}$. These concentrations of statins were chosen as they are considered to be close to those detected in the human body when administered therapeutically. Supernatants from each culture condition were assessed for MMP-1 and -3 release by Western blot analysis, and for MMP-2 and -9 by gelatine zymography. As expected, the cytokines stimulated MMP-1 and -3 release (fig. 1a-d). Bands corresponding to the latent forms (55 kDa) were observed, but lower molecular weight bands corresponding to active MMPs were not observed. All three statins inhibited both MMP-1 (fig. 1a and b) and MMP-3 (fig. 1c and d) release stimulated by cytokines $(\mathrm{p}<0.05$ compared with the cytokine-treated controls). In monolayer culture, MMP-9 release was not observed under any condition. However, HFL-1 cells released a gelatinase corresponding to the latent form of MMP-2 (fig. 1e and f). The effect of atorvastatin on the release of the latent form of MMP-2 stimulated by cytokines was modest (fig. 1e and f). None of the reagents affected cell viability evaluated by MTT assay (data not shown).

To determine whether the inhibition of MMP-1 and -3 expression by atorvastatin was associated with changes in gene expression, quantitative real-time PCR was performed after $6 \mathrm{~h}$ of incubation with statins and cytokines (TNF- $\alpha 5 \mathrm{ng} \cdot \mathrm{mL}^{-1}$ and IL-1 $\left.\beta 2 \mathrm{ng} \cdot \mathrm{mL}^{-1}\right)$. Atorvastatin alone slightly stimulated both MMP-1 (fig. 2a) and MMP-3 (fig. 2b) mRNA expression. However, this effect was modest compared with that of the cytokines, which stimulated MMP-1 and -3 mRNA 121.6 $\pm 3.8-$ and $46.9 \pm 1.0$-fold of control, respectively. When cells were treated with atorvastatin before the stimulation by cytokines, the effect of the cytokines on both MMP-1 and -3 mRNA was inhibited to $12.3 \pm 1.4$ - and $7.1 \pm 0.4$-fold of control, respectively ( $\mathrm{p}<0.01$ compared with the cytokine treated groups). Consistent with the results observed with gelatine zymography, no MMP-9 mRNA was detected (data not shown).

\section{Adult lung fibroblasts}

Because fibroblasts may be functionally heterogeneous, we also investigated the effect of atorvastatin on the inhibition of MMP release from normal adult human lung fibroblasts (HLF) after $24 \mathrm{~h}$ of culture. In contrast to HFL-1 cells, which did not release any detectable MMP-1 or -3 under control conditions, HLF cells released a small amount of MMP-1 and -3 corresponding in molecular size to the latent form of $55 \mathrm{kDa}$ (online supplementary material fig. 1). As with HFL-1 cells, the cytokines also stimulated both MMP-1 and -3 release from HLF cells (online supplementary material fig. 1a-d). Also, as with HFL-1 cells, atorvastatin inhibited HLF release of both 
a)

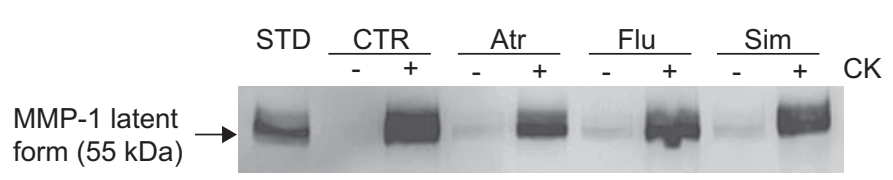

c)

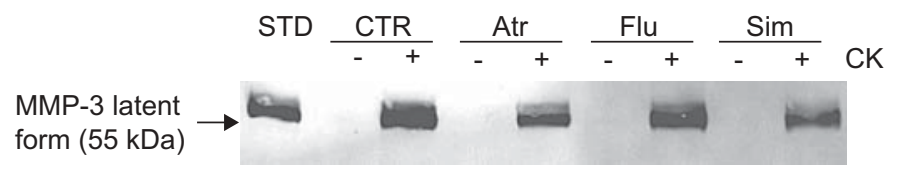

e)

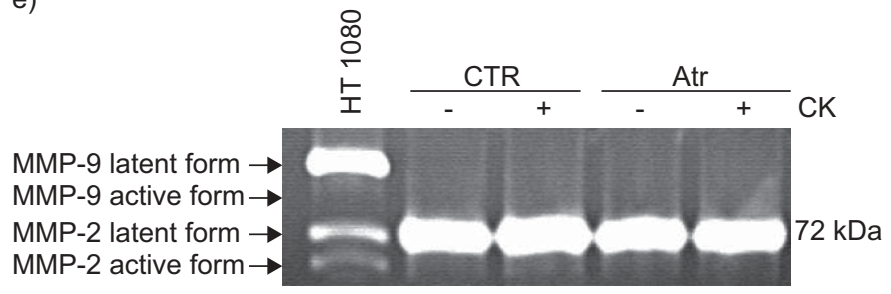

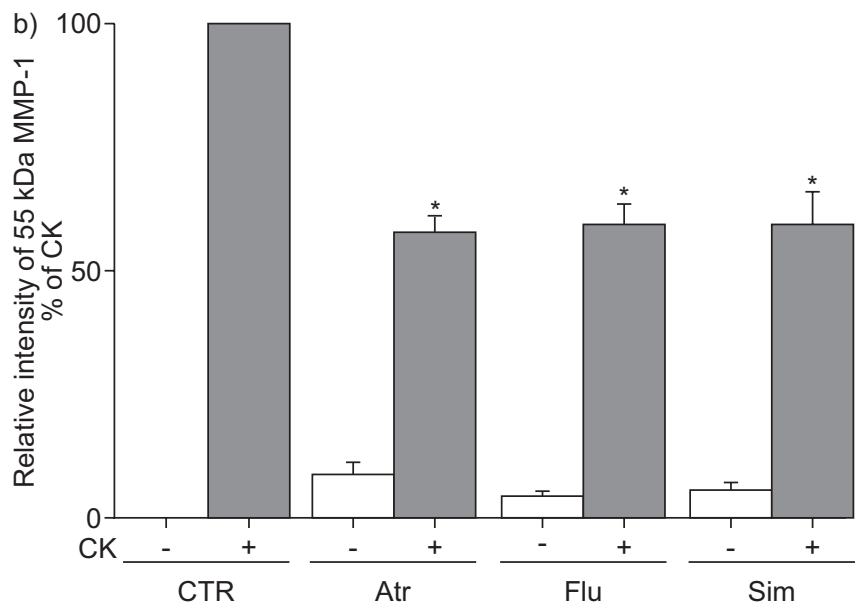
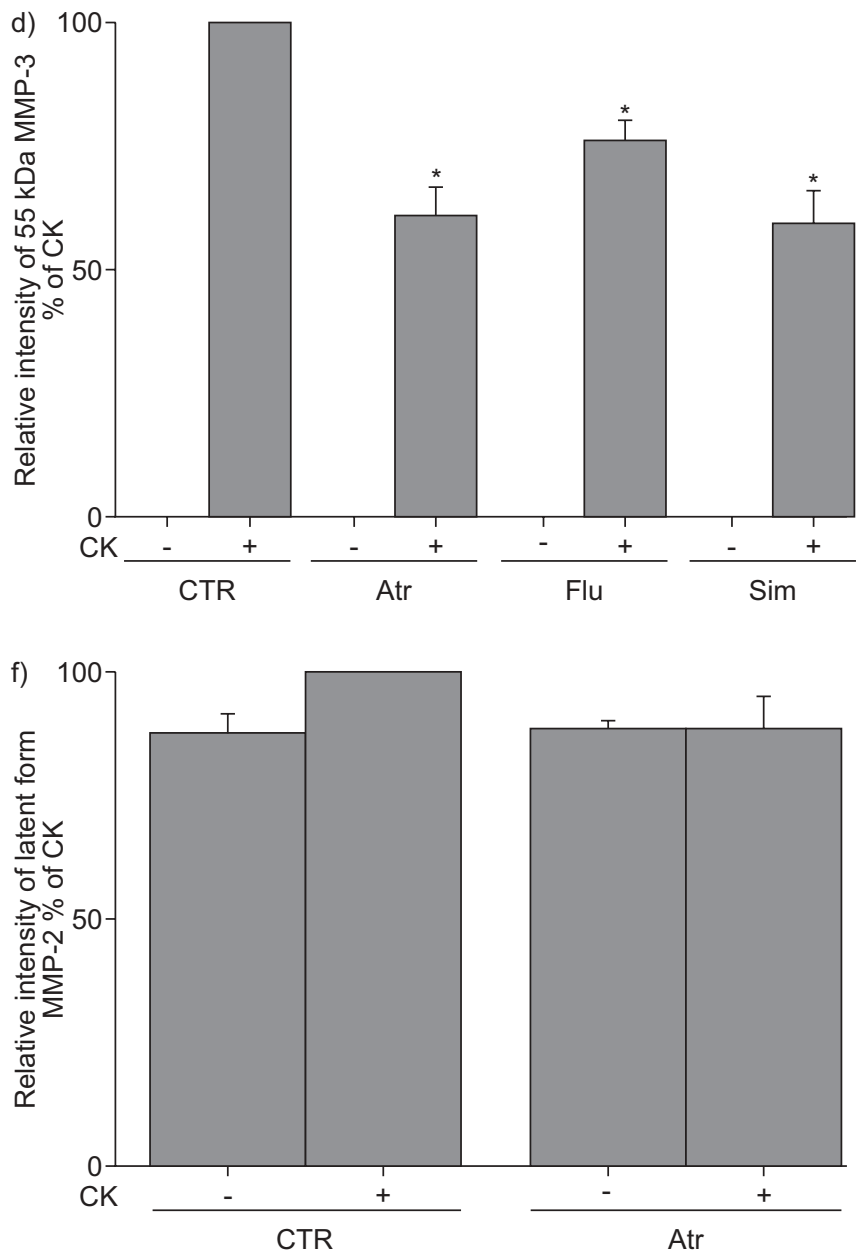

FIGURE 1. Effect of statins on matrix metalloproteinase (MMP) release by fibroblasts in monolayer culture. Human fetal lung fibroblast-1 cells cultured in monolayer were treated with atorvastatin (Atr; $2.5 \mu \mathrm{M}$ ), fluvastatin (Flu; $1.0 \mu \mathrm{M}$ ) and simvastatin (Sim; $0.5 \mu \mathrm{M})$. $1 \mathrm{~h}$ later, cytokines (CK; tumour necrosis factor- $\alpha 5 \mathrm{ng} \cdot \mathrm{mL}^{-1}$ and interleukin-1 $\alpha$ $2 \mathrm{ng} \cdot \mathrm{mL}^{-1}$ ) were added. Supernatant media harvested after $24 \mathrm{~h}$ were subjected to Western blot analysis for MMP-1 and MMP-3, and gelatine zymography for MMP-2 and MMP-9. a) MMP-1 western blot. The band corresponding to the latent form is indicated by the arrow. b) Quantification of MMP-1 staining. c) MMP-3 western blot. The band corresponding to the latent form of MMP-3 is indicated by the arrow. d) Quantification of MMP-3 staining. e) Gelatine zymography for MMP-2 and MMP-9. f) Quantification of MMP-2 staining. Densitometry data are shown as mean \pm SEM from three separate experiments performed on different occasions. STD: MMP-1 and MMP-3 standards; CTR: control; HT1080: supernatant from HT1080 cell monolayer culture as a positive control. *: $p<0.05$ compared with the cytokine-treated controls. 

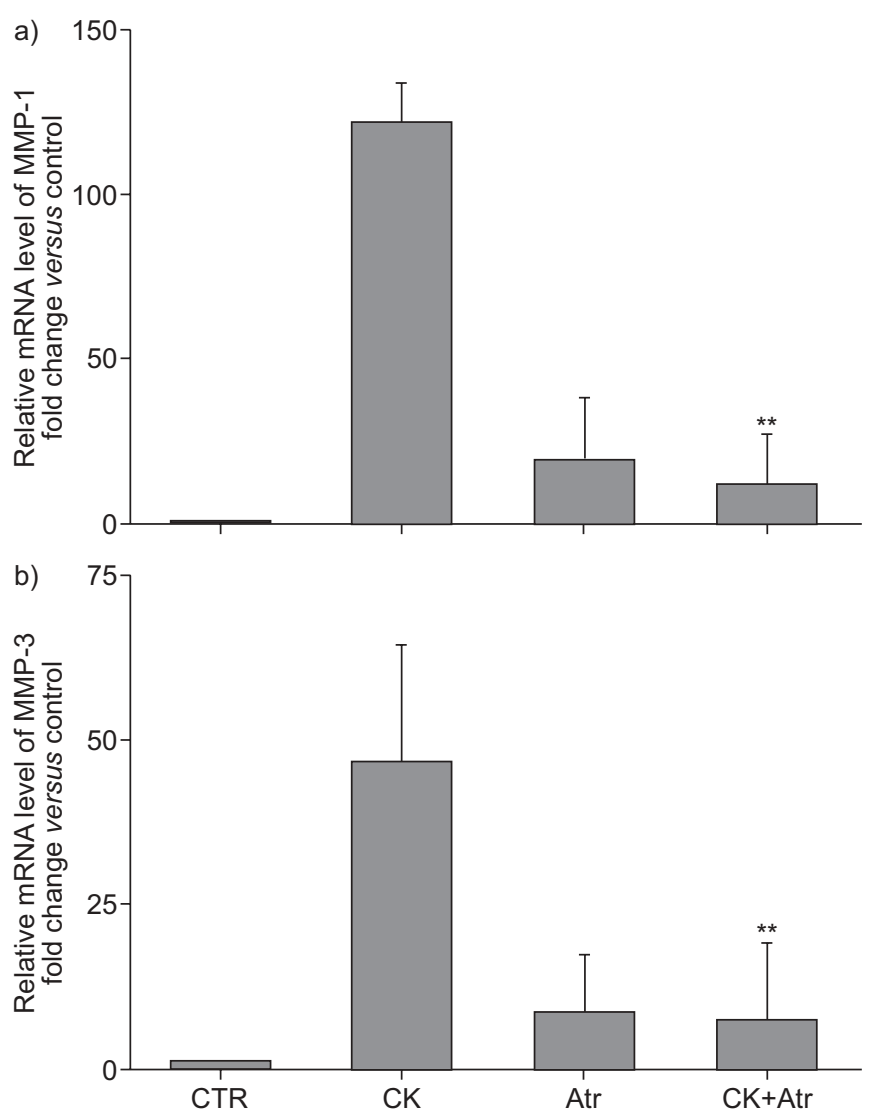

FIGURE 2. Effect of atorvastatin (Atr) on a) matrix metalloproteinase (MMP)-1 and b) MMP-3 mRNA expression. Human fetal lung fibroblast-1 fibroblasts cultured in monolayer were treated with and without atorvastatin $(2.5 \mu \mathrm{M}) .1 \mathrm{~h}$ later, cytokines (CK; tumour necrosis factor- $\alpha 5 \mathrm{ng} \cdot \mathrm{mL}^{-1}$ and interleukin-1 $\alpha 2 \mathrm{ng} \cdot \mathrm{mL}^{-1}$ ) were added and then cultured for $6 \mathrm{~h}$. mRNA levels were quantified by Taqman RTPCR. The vertical axes show mRNA expression level normalised to the amount of rRNA and expressed as fold of control. The data presented are mean \pm SEM from three separate experiments, each performed in duplicate. CTR: control. ${ }^{* *}: p<0.01$ compared with cytokine treated groups.

MMP-1 (online supplementary material fig. $1 \mathrm{a}$ and b) and MMP-3 (online supplementary material fig. 1c and $\mathrm{d}$ ) release stimulated by cytokines $(\mathrm{p}<0.05$ compared with the cytokinetreated controls). The release of MMP-2 was similar to that of HFL-1 cells and, as with HFL-1 cells, MMP-9 was not detected in the supernatant of HLF cells in monolayer cultures (online supplementary material fig. 1e and f).

\section{Role of the mevalonate pathway}

Inhibition of MMP-1 and MMP-3 protein release

Incubation of cells with HMG-CoA reductase inhibitors, such as the statins, blocks production of mevalonate [28, 29]. Mevalonate metabolism yields a series of isoprenoids, including FPP and GGPP. To confirm that this is the pathway by which atorvastatin inhibits MMP-1 and -3 release, we tested whether mevalonate, FPP or GGPP could reverse atorvastatin inhibition of cytokine-stimulated HFL-1 MMP-1 and -3 release. HFL-1 cells were cultured in monolayer and treated with atorvastatin $(2.5 \mu \mathrm{M})$ with or without mevalonate $(100 \mu \mathrm{M})$, FPP $(5 \mu \mathrm{M})$ or GGPP $(5 \mu \mathrm{M})$ followed by stimulation with cytokines (TNF- $\alpha 5 \mathrm{ng} \cdot \mathrm{mL}^{-1}$ and IL-1 $\beta 2 \mathrm{ng} \cdot \mathrm{mL}^{-1}$ ) for $24 \mathrm{~h}$. In the presence of mevalonate, GGPP or FPP alone, there was no detectable level of MMP-1 release (fig. 3a) and this corresponded to the results under control conditions (data not shown). The addition of mevalonate and GGPP almost completely blocked the inhibitory effect of atorvastatin on the release of MMP-1 (fig. $3 a$ and $b ; p<0.05$ compared with cytokine-treated groups after incubation with atorvastatin). In contrast, FPP had no effect.

No MMP-3 was detected when cells were incubated under control conditions (data not shown) or with mevalonate, GGPP or FPP added alone (fig. 3c). Mevalonate and GGPP blocked the inhibitory effect of atorvastatin on MMP-3 release that was stimulated by cytokines (fig. $3 \mathrm{c}$ and $\mathrm{d} ; \mathrm{p}<0.05$ compared with cytokine-treated groups after incubation with atorvastatin). FPP was without effect.

\section{Inhibition of MMP-1 and MMP-3 mRNA expression}

To determine whether the effects of mevalonate and GGPP were associated with changes in gene expression, quantitative real-time PCR assay was performed. HFL-1 cells were treated with atorvastatin $(2.5 \mu \mathrm{M})$ with or without mevalonate $(100 \mu \mathrm{M})$ or GGPP $(5 \mu \mathrm{M})$, and then stimulated with cytokines $\left(\mathrm{TNF}-\alpha \quad 5 \mathrm{ng} \cdot \mathrm{mL}^{-1}\right.$ and IL-1 $\beta 2 \mathrm{ng} \cdot \mathrm{mL}^{-1}$ ) for $6 \mathrm{~h}$. Neither mevalonate nor GGPP alone altered MMP-1 or -3 mRNA expression levels (fig. $4 a$ and $b$, respectively; $p<0.01$ compared with cytokines plus atorvastatin treated groups). However, the addition of mevalonate or GGPP blocked the inhibitory effect of atorvastatin on MMP-1 and - 3 mRNA expression significantly (fig. 4a and b, respectively). FPP did not have any effect on MMP-1 or -3 mRNA expression (data not shown).

\section{Culture in $3 D$ collagen gels}

\section{Effect of atorvastatin on collagen degradation}

The response of fibroblasts to exogenously added mediators can vary depending on the culture condition. In 3D cultures in floating collagen gels, which are thought to more closely mimic in vivo conditions, we have previously shown that stimulation of fibroblasts with cytokines in the presence of NE can result in degradation of the collagen gel matrix [19]. To determine if atorvastatin inhibition of fibroblast MMP release could lead to inhibition of matrix degradation, we prepared 3D collagen gels populated with HFL-1 fibroblasts. When stimulated by cytokines (TNF- $\alpha 5 \mathrm{ng} \cdot \mathrm{mL}^{-1}$ and IL-1 $2 \mathrm{ng} \cdot \mathrm{mL}^{-1}$ ) to induce MMP release in the presence of NE $(10 \mathrm{nM})$, which leads to activation of MMPs, the collagen gels were degraded as we have reported previously [19]. The hydroxyproline content of the gels was significantly reduced after 3 days (hydroxyproline content $38 \pm 4 \%$ of control (fig. 5); $\mathrm{p}<0.05$ compared with control). This decrease was almost completely inhibited by atorvastatin (hydroxyproline content $83 \pm 8 \%$ of control (fig. 5); $\mathrm{p}<0.05$ compared with cytokine $+\mathrm{NE})$. Hydroxyproline content of gels treated with atorvastatin + cytokines (without $\mathrm{NE}$ ) or atorvastatin + NE (without cytokines) was the same as that of control (data not shown).

\section{Effect of atorvastatin on MMP release}

To confirm the results obtained in monolayer culture on plastic, we also assessed the effect of atorvastatin on MMP release in $3 \mathrm{D}$ culture in collagen gels. There were modest 
a)

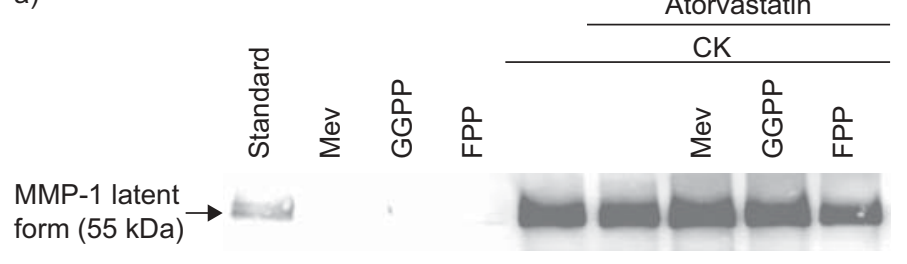

c)

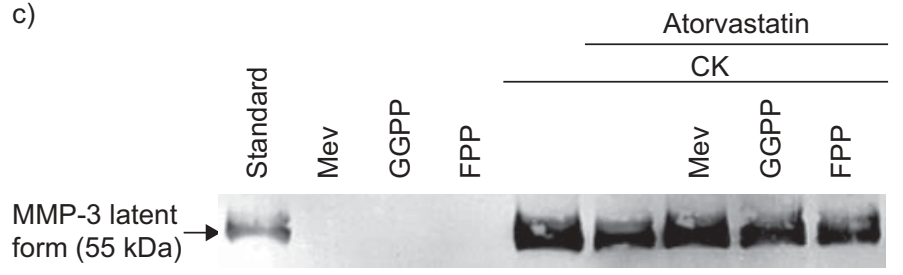

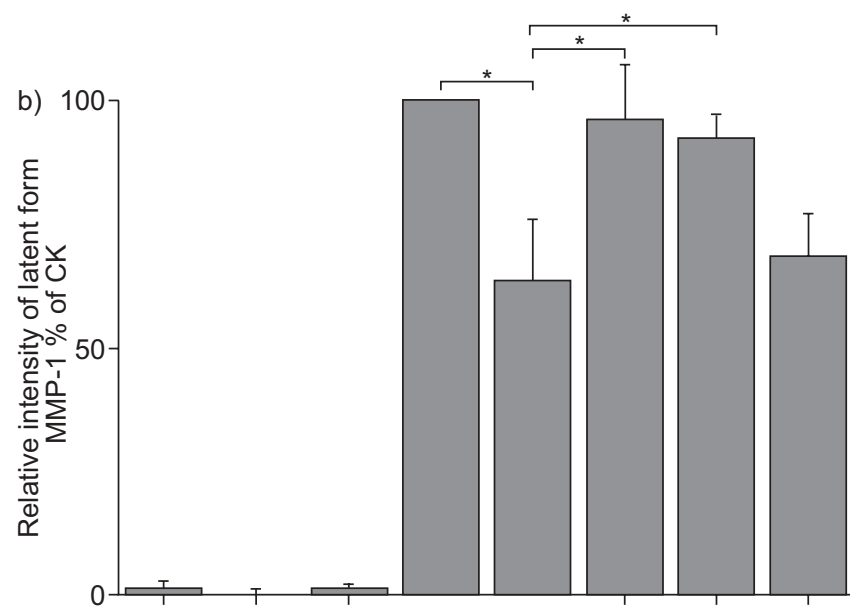

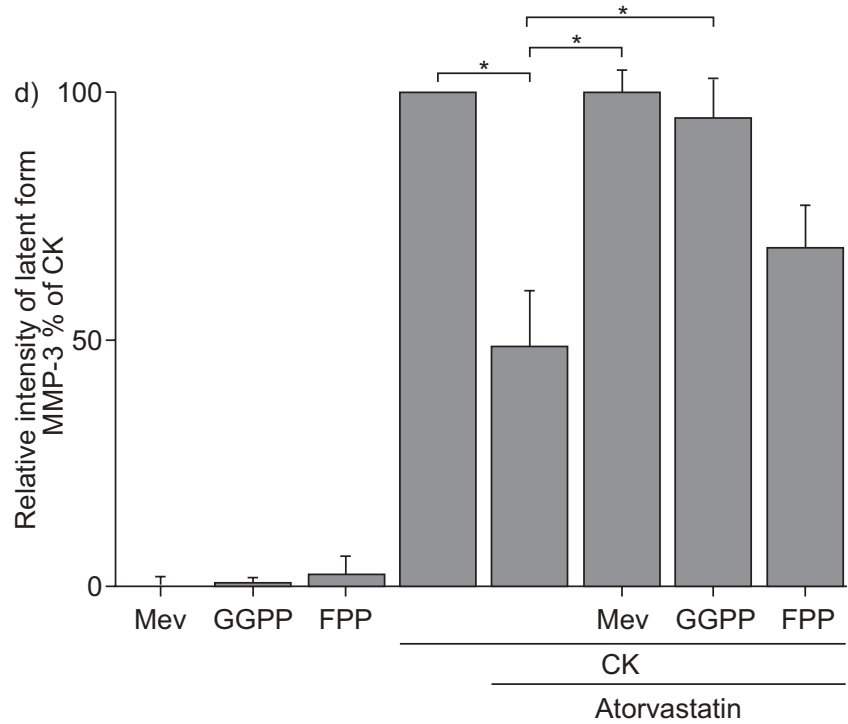

FIGURE 3. Effect of mevalonate (Mev) and isoprenoids on atorvastatin inhibition of a) MMP-1 and b) MMP-3 release. Human fetal lung fibroblast-1 cells were cultured in monolayer and treated with atorvastatin $(2.5 \mu \mathrm{M})$ with or without Mev, geranylgeranyl pyrophosphate (GGPP) or farnesyl pyrophosphate (FPP). $1 \mathrm{~h}$ later, cytokines (CK; tumour necrosis factor- $\alpha 5 \mathrm{ng} \cdot \mathrm{mL}^{-1}$ and interleukin-1 $\alpha 2 \mathrm{ng} \cdot \mathrm{mL}^{-1}$ ) were added. Supernatant media harvested after $24 \mathrm{~h}$ were subjected to Western blot analysis for MMP-1 and MMP-3. a) MMP-1 and c) MMP-3 Western blots. The band corresponding to the latent form is indicated by the arrow. Quantification of b) MMP-1 and d) MMP-3 staining Densitometry data are shown as mean \pm SEM for three separate experiments performed on separate occasions. *: $p<0.05$.

differences in MMP release under control conditions. For example, detectable MMP-1 was released in latent form under control conditions in 3D culture, which contrasts with the undetectable levels in monolayer culture. Importantly, as with monolayer culture, there was marked increase in release of MMP-1 following cytokine stimulation (online supplementary material fig. 2). As in monolayer culture, MMP-3 was undetectable under control conditions in 3D culture (online supplementary material fig. 3). MMP-2, which was released in the latent form in monolayer culture, was released in both latent and active forms under control conditions in 3D culture (online supplementary material fig. 4). MMP-9, which was not released under any conditions tested in monolayer culture, was not released under control conditions in 3D culture, but its release was stimulated by cytokines (TNF- $\alpha 5 \mathrm{ng} \cdot \mathrm{mL}^{-1}$ and IL- $1 \alpha$ $2 \mathrm{ng} \cdot \mathrm{mL}^{-1}$ ) (online supplementary material fig. 4). Importantly, the cytokines stimulated the release of all the MMPs assessed, MMP-1, -3 and -9 , and this release was inhibited $(p<0.05$ compared with cytokines) in all cases by atorvastatin (online supplementary material figs 2, 3 and 4). There was, moreover, a reduction in the conversion of latent MMPs to the active forms in the presence of NE for MMP-1 $(p<0.05),-3(p<0.01)$ and -9 $(p<0.001)$. A modest effect, which was not quantified, was also observed in inhibiting MMP-2 release (online supplementary material fig. 4a).

\section{Role of the mevalonate pathway in inhibition of collagen gel degradation}

To confirm that atorvastatin inhibited collagen gel degradation by the same pathway by which it inhibited MMP release in monolayer culture, we assessed the ability of mevalonate $(100 \mu \mathrm{M}), \mathrm{FPP}(5 \mu \mathrm{M})$ and GGPP $(5 \mu \mathrm{M})$ to block atorvastatin inhibition of collagen gel degradation induced by the combination of cytokines and NE. After 3 days of culture in the presence of cytokines and NE, collagen gel hydroxyproline content was reduced by more than half (online supplementary 

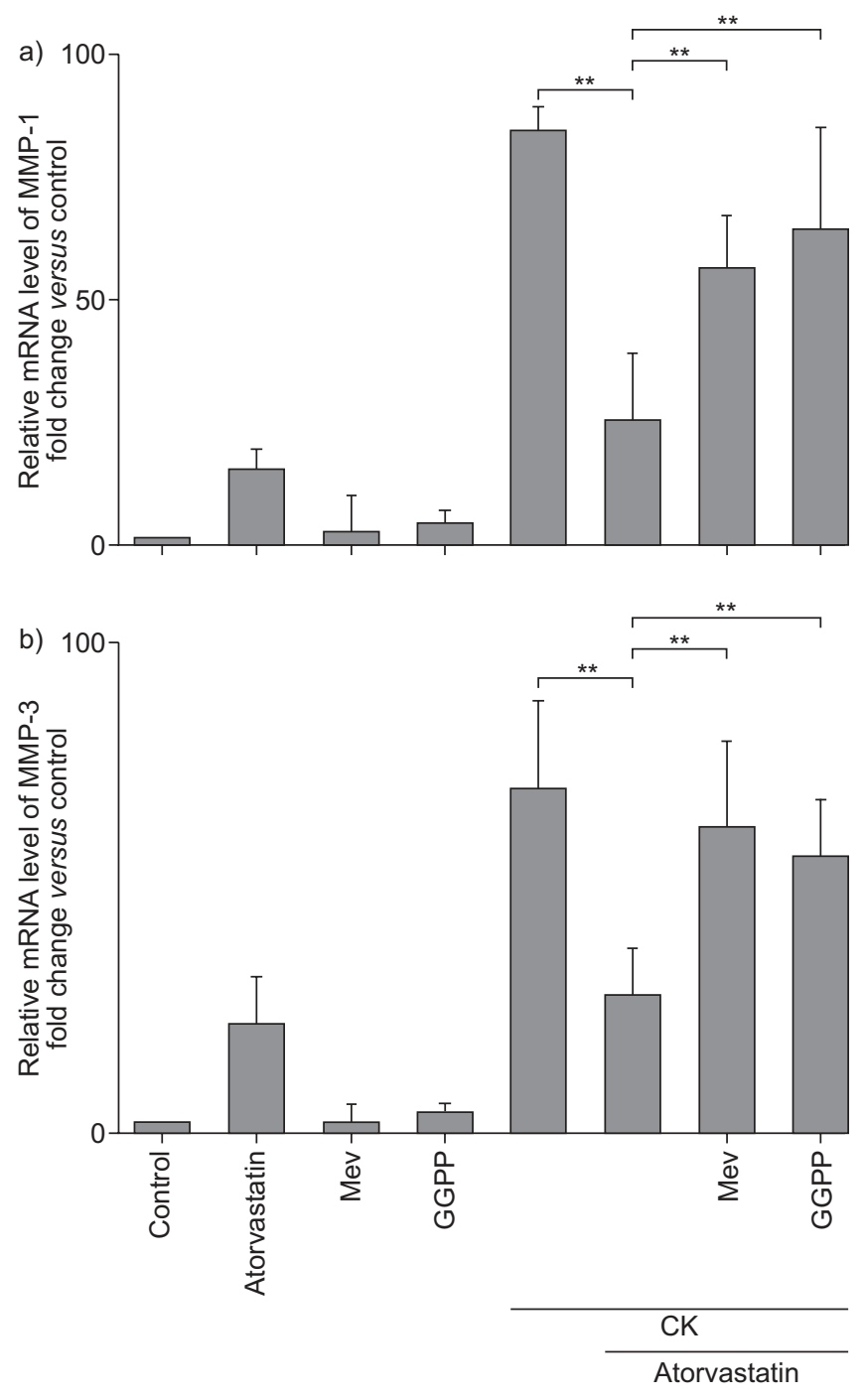

FIGURE 4. Effect of mevalonate (Mev) and isoprenoids on atorvastatin inhibition of a) matrix metalloproteinase (MMP)-1 and b) MMP-3 mRNA expression. Human fetal lung fibroblast -1 cells were cultured in monolayer and treated with atorvastatin $(2.5 \mu \mathrm{M})$ with or without Mev or geranylgeranyl pyrophosphate (GGPP). $1 \mathrm{~h}$ later, cytokines (CK; tumour necrosis factor- $\alpha 5 \mathrm{ng} \cdot \mathrm{mL}^{-1}$ and interleukin-1 $\alpha 2 \mathrm{ng} \cdot \mathrm{mL}^{-1}$ ) were added and cultured for $6 \mathrm{~h}$. mRNA levels were quantified by Taqman RT-PCR. Vertical axes show the mRNA expression level normalised to the amount of rRNA and expressed as fold of control. The data presented are mean \pm SEM from three separate experiments, each performed in duplicate. ${ }^{*}$ : $p<0.01$.

material fig. 5; $\mathrm{p}<0.05$ compared with control), indicating degradation of the collagen gels. Atorvastatin almost completely inhibited this degradation $(\mathrm{p}<0.05$ compared with cytokines + NE). Mevalonate and GGPP had no effect when added alone, but almost completely reversed atorvastatin inhibition of collagen degradation caused by cytokines and NE (fig. 3; $\mathrm{p}<0.05$ compared with control). In contrast, FPP had no effect when added alone and did not reverse the inhibitory effect of atorvastatin on collagen gel degradation.

\section{Role of the mevalonate pathway in 3D culture}

Because fibroblasts in 3D culture release MMP somewhat differently than in monolayer culture, we also investigated

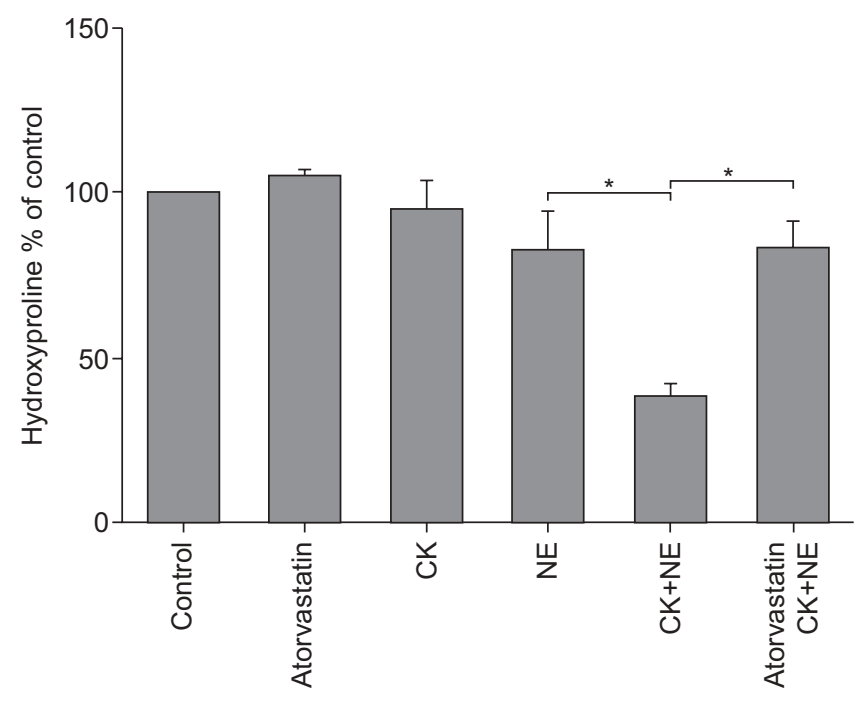

FIGURE 5. Effect of atorvastatin on collagen gel degradation induced by cytokines $(\mathrm{CK})$ together with neutrophil elastase (NE). Human fetal lung-1 fibroblasts $\left(3 \times 10^{5}\right.$ cells $\left.\cdot \mathrm{mL}^{-1}\right)$ were cast into three-dimensional collagen gels and released into floating media (serum-free Dulbecco's modified Eagle's medium) containing atorvastatin $(2.5 \mu \mathrm{M}) .1 \mathrm{~h}$ later, $\mathrm{CK}$ (tumour necrosis factor- $\alpha 5 \mathrm{ng} \cdot \mathrm{mL}^{-1}$ and interleukin-1 $\alpha 2 \mathrm{ng} \cdot \mathrm{mL}^{-1}$ ) were added; NE was added the next day. The gels were cultured for three more days and hydroxyproline content in the gels was determined. The data presented are mean \pm SEM from three separate experiments, each of which included triplicate gels for each condition. ${ }^{*}: p<0.05$.

whether mevalonate or isoprenoids blocked the effect of atorvastatin on MMP release in 3D gel culture (online supplementary material fig. 6). Although statistical significance was not achieved, there was a trend for both mevalonate and GGPP to block the inhibitory effect of atorvastatin on the amount of detectable active MMP-1 released in the presence of cytokines and NE (online supplementary material fig. 6a and b). Both mevalonate and GGPP significantly blocked the inhibitory effect of atorvastatin on MMP-3 release (online supplementary material fig. $6 \mathrm{c}$ and $\mathrm{d} ; \mathrm{p}<0.01$ ) and on the release of MMP-9 and its conversion to an $84 \mathrm{kDa}$ size that corresponds to the active form MMP-9 (online supplementary material fig. 6e and f; $\mathrm{p}<0.01)$. FPP was consistently without effect.

\section{Adult HLF in 3D culture}

\section{Collagen degradation}

To confirm that collagen gel degradation occurs in the gels populated with adult HLF and that MMP release by these cells is also blocked by atorvastatin, cultured HLF cells were cast into 3D cultures and treated with cytokines and NE to induce degradation. As observed with HFL-1 cells, in the presence of cytokines and NE, hydroxyproline content of the gels was significantly reduced after 3 days of culture (online supplementary material fig. $7 ; \mathrm{p}<0.05$ compared with control). This decrease was inhibited by atorvastatin $(\mathrm{p}<0.05$ compared with cytokines $+\mathrm{NE})$. The role of the mevalonate pathway also appeared to be the same in HLF cells, as mevalonate and GGPP had no effect when added alone, but reversed the effect of atorvastatin on the inhibition of collagen degradation caused by cytokines and NE (online supplementary material fig. 7; $\mathrm{p}<0.05$ compared with control). 


\section{DISCUSSION}

The current study demonstrates that HMG-CoA reductase inhibitors can inhibit cytokine-induced release of MMPs from human lung fibroblasts cultured in both monolayer and 3D collagen gels. Release of both MMP-1 and -3 from fibroblasts in monolayer culture was inhibited by atorvastatin, simvastatin and fluvastatin. Atorvastatin also inhibited the cytokineinduced expression of MMP-1 and MMP-3 mRNA expression. In $3 \mathrm{D}$ gel culture, atorvastatin inhibited the degradation of collagen gels that was induced by cytokines in the presence of NE. In contrast to monolayer culture, in 3D gel culture, fibroblasts were induced by cytokines to release MMP-9, and these were also inhibited by atorvastatin. All of these changes were reversed by the addition of mevalonate and GGPP, which are intermediates in the HMG-CoA reductase pathway that bypass the step inhibited by statins. Interestingly, the intermediate FPP did not reverse these effects of atorvastatin. Taken together, the current data suggest that statins may modulate remodelling processes mediated by lung fibroblasts by inhibiting the release of MMPs.

Since the classic studies of LAURELL and ERIKSSON [30], proteases have been believed to play a major role in the pathogenesis of COPD. In particular, the MMPs have been suggested to play a prominent role. In support of this concept, mice deficient in the macrophage elastase MMP-12 have been reported to be resistant to the development of cigarette smokeinduced emphysema [31], although MMP-12 is not prominent in human emphysema [32]. Increased MMP-9 expression in the lungs has been reported to be associated with emphysema, in both experimental [33-37] and clinical [38] studies. Moreover, immunohistochemical analysis of COPD lungs showed an increased expression of collagenase 1 (MMP-1) and collagenase 2 (MMP-8) [39], and alveolar epithelial cells from patients with emphysema express MMP-1 mRNA and protein, and exhibit collagenase activity [40].

MMPs are expressed in low to undetectable levels in normal lung, but are readily detected in many lung diseases in addition to emphysema. In this context, the expression of MMPs is not restricted to inflammatory cells; virtually all cells, including alveolar epithelial cells and fibroblasts, can make MMPs [40, 41]. Alveolar fibroblasts, which comprise $\sim 40 \%$ of alveolar cells [42], are believed to be the major cells responsible for the production and remodelling of ECM. They are one of the major sources of MMPs, which are secreted following lung injury. Therefore, inhibition of MMP release from fibroblasts could confer a new therapeutic approach to prevent the lung destruction observed in emphysema. Whether inhibition by statins could lead to toxicities, e.g. by inhibiting lung tissue turnover in fibrotic areas, of course, is a potential toxicity that would need to be considered.

Statins were originally developed for their cholesterol-lowering properties and efficacy in cardiovascular disease. However, evidence of pleiotropic effects of statins has been accumulating and suggests immunomodulatory, antioxidant, antithrombogenic and vascular actions [7, 29]. Several statins have been reported to inhibit the expression of MMPs in vascular cells and macrophages in vitro [9-11]. Consistent with this effect on MMPs, statins have been reported to inhibit the development of emphysema in model systems. In a rat model of cigarette smoking-induced emphysema, LEE et al. [43] found that simvastatin inhibited lung parenchymal destruction and MMP-9 expression. In a mouse model of emphysema induced by elastase, simvastatin reduced mRNA expression for interferon- $\gamma$, TNF- $\alpha$ and MMP-12 in the whole lung [44].

The current study extends these observations by providing a basis for statins to alter lung structural remodelling by a direct effect on fibroblast MMP release. Further, our study demonstrates that the effect of the statins is mediated through the mevalonate pathway, which is likely to involve GGPP but not FPP. This observation is similar to other studies, which also observed that the addition of FPP did not reverse the effect of statins $[45,46]$. The mechanism for the failure of FPP to reverse these statin effects remains unexplained.

As with the normal lung, fibroblasts in culture release very low amounts of MMP-1, $-2,-3$ and -9 . The release of these MMPs, however, can be readily induced by the inflammatory cytokines TNF- $\alpha+$ IL-1 $\beta$, and it is the induced MMP release that statins were demonstrated to inhibit in the current study. This inhibition occurred both in the more conventionally used monolayer culture system (on plastic dishes) and in culture in $3 \mathrm{D}$ collagen gels, a system that is believed to more closely resemble tissue conditions [14, 16, 47]. In this system, degradation of the ECM can be quantified, and statins also inhibited this process. Some modest differences were observed between cells grown in monolayer and 3D culture. Part of these differences could be related to MMP retention in the collagen gel in the 3D system. This is unlikely, however, to account for the production of MMP-9 in 3D culture, which was not observed in monolayer culture. While there were some differences between the culture systems, the consistency of the inhibitory effects of statins, which were also observed in both the fetal strain of fibroblasts HFL-1 that has been widely used to explore lung fibroblast biology and in a strain of normal adult fibroblasts, suggests that the inhibitory effects of statins are robust.

In the current study, statins slightly increased the release of MMP-1 when added alone, and this was confirmed at both the mRNA and protein levels. Atorvastatin also slightly increased MMP-3 mRNA when added alone; however, MMP-3 was not detected at the protein level. The mechanisms that lead to mild stimulation when added alone and marked inhibition when added together with cytokines are unclear, but similar effects have been observed in other regulatory networks when agents can have multiple effects. These observations, therefore, suggest that statins might be modulating MMP release at several levels.

In summary, the current study demonstrates that statins can inhibit MMP release from HLFs in both monolayer and 3D collagen gel cultures. This effect is mediated through the inhibition of the HMG-CoA reductase pathway. Through actions on fibroblast MMP release, statins may modulate remodelling processes mediated by fibroblasts. The use of statins, therefore, may have therapeutic potential in diseases characterised by alterations in tissue architecture, particularly diseases characterised by tissue destruction, such as emphysema. 


\section{SUPPORT STATEMENT}

Funded by a grant from Pfizer Pharmaceaticals.

\section{STATEMENT OF INTEREST}

A statement of interest for S.I. Rennard, and this study itself can be found at www.erj.ersjournals.com $/ \mathrm{misc} /$ statements.dtl

\section{ACKNOWLEDGEMENTS}

The authors thank the excellent secretarial support of L. Richards.

\section{REFERENCES}

1 Murray CJ, Lopez AD. Alternative projection of mortality by cause 1990-2020: global burden of disease study. Lancet 1997; 349: 14981504.

2 World Health Organization, Global strategy for diagnosis, management and prevention of COPD, 2007. www.goldcopd. com Date last updated: January, 2009. Date last accessed: November 30, 2009.

3 Mancini GB, Etminan M, Zhang B, et al. Reduction of morbidity and mortality by statins, angiotensin-converting enzyme inhibitors, and angiotensin receptor blockers in patients with chronic obstructive pulmonary disease. J Am Coll Cardiol 2006; 47: 25542560.

4 Ishida W, Kajiwara T, Ishii M, et al. Decrease in mortality rate of chronic obstructive pulmonary disease (COPD) with statin use: a population-based analysis in Japan. Tohoku J Exp Med 2007; 212: 265-273.

5 Soyseth V, Brekke PH, Smith P, et al. Statin use is associated with reduced mortality in COPD. Eur Respir J 2007; 29: 279-283.

6 Keddissi JI, Younis WG, Chbeir EA, et al. The use of statins and lung function in current and former smokers. Chest 2007; 132 1764-1771.

7 Bonetti PO, Lerman LO, Napoli C, et al. Statin effects beyond lipid lowering - are they clinically relevant? Eur Heart J 2003; 24: 225248.

8 Hothersall E, McSharry C, Thomson NC. Potential therapeutic role for statins in respiratory disease. Thorax 2006; 61: 729-734.

9 Ikeda U, Shimpo M, Ohki R, et al. Fluvastatin inhibits matrix metalloproteinase-1 expression in human vascular endothelial cells. Hypertension 2000; 36: 325-329.

10 Bellosta S, Via D, Canavesi M, et al. HMG-CoA reductase inhibitors reduce MMP-9 secretion by macrophages. Arterioscler Thromb Vasc Biol 1998; 18: 1671-1678.

11 Luan Z, Chase AJ, Newby AC. Statins inhibit secretion of metalloproteinases-1, $-2,-3$, and -9 from vascular smooth muscle cells and macrophages. Arterioscler Thromb Vasc Biol 2003; 23: 769-775.

12 Parks WC, Shapiro SD. Matrix metalloproteinases in lung biology. Respirat Res 2001; 2: 10-19.

13 Hogg JC, Senior RM. Chronic obstructive pulmonary disease - part 2: pathology and biochemistry of emphysema. Thorax 2002; 57: 830-834.

14 Grinnell F. Fibroblasts, myofibroblasts and wound contraction. J Cell Biol 1994; 124: 401-404.

15 Breul SD, Bradley $\mathrm{KH}$, Hance $\mathrm{AJ}$, et al. Control of collagen production by human diploid lung fibroblasts. J Biol Chem 1980; 255: 5250-5260.

16 Elsdale T, Bard J. Collagen substrata for studies on cell behavior. J Cell Biol 1972; 54: 626-637.

17 Mio T, Adachi Y, Romberger DJ, et al. Regulation of fibroblast proliferation in three dimensional collagen gel matrix. In vitro Cell Dev Biol 1996; 32: 427-433.

18 Reddy GK, Enwemeka CS. A simplified method for the analysis of hydroxyproline in biological tissues. Clin Biochem 1996; 29: 225-229.
19 Zhu YK, Liu XD, Skold CM, et al. Synergistic neutrophil elastase-cytokine interaction degrades collagen in threedimensional culture. Am I Physiol Lung Cell Mol Physiol 2001; 281: L868-L878.

20 Fang Q, Liu X, Al-Mugotir M, et al. Thrombin and TNF- $\alpha / \mathrm{IL}-1 \beta$ synergistically induce fibroblast-mediated collagen gel degradation. Am J Respir Cell Mol Biol 2006; 35: 714-721.

21 Henry MT, McMahon K, Mackarel AJ, et al. Matrix metalloproteinases and tissue inhibitor of metalloproteinase-1 in sarcoidosis and IPF. Eur Respir J 2002; 20: 1220-1227.

22 Kubo S, Kobayashi M, Masunaga Y, et al. Cytokine and chemokine expression in cigarette smoke-induced lung injury in guinea pigs. Eur Respir J 2005; 26: 993-1001.

23 Zhang Y, McCluskey K, Fujii K, et al. Differential regulation of monocyte matrix metalloproteinase and TIMP-1 production by TNF-alpha, granulocyte-macrophage CSF, and IL-1 $\beta$ through prostaglandin-dependent and -independent mechanisms. J Immunol 1998; 161: 3071-3076.

24 Zhu YK, Liu XD, Sköld CM, et al. Collaborative interactions between neutrophil elastase and metalloproteinases in extracelullar matrix degradation in three-dimensional collagen gels. Respir Res 2001; 2: 300-305.

25 Chomczynski P, Sacchi N. Single-step method of RNA isolation by acid guanidine thiocyanate-phenol-chloroform extraction. Anal Biochem 1987; 162: 156-159.

26 Bustin SA. Absolute quantification of mRNA using real-time reverse transcription polymerase chain reaction assays. J Mol Endocrinol 2000; 25: 169-193.

27 Supino R. MTT assays. Methods Mol Biol 1995; 43: 137-149.

28 Goldstein JL, Brown MS. Regulation of the mevalonate pathway. Nature 1990; 343: 425-430.

29 Greenwood J, Steinman L, Zamvil SS. Statin therapy and autoimmune disease: from protein prenylation to immunomodulation. Nat Rev Immunol 2006; 6: 358-370.

30 Laurell CB, Eriksson S. The electrophoretic $\alpha$ 1-globulin pattern of serum in $\alpha$ 1-antitrypsin deficiency. Scand J Clin Lab Invest 1963; 15 132-140.

31 Hautamaki RD, Kobayashi DK, Senior RM, et al. Requirement for macrophage elastase for cigarette smoke-induced emphysema in mice. Science 1997; 277: 2002-2004

32 Finlay GA, O'Driscoll LR, Russell KJ, et al. Matrix metalloproteinase expression and production by alveolar macrophages in emphysema. Am J Crit Care Med 1997; 156: 240-247.

33 Selman M, Cisneros-Lira J, Gaxiola M, et al. Matrix metalloproteinases inhibition attenuates tobacco smoke-induced emphysema in Guinea pigs. Chest 2003; 123: 1633-1641.

34 Zheng $\mathrm{T}$, Zhu $\mathrm{Z}$, Wang $\mathrm{Z}$, et al. Inducible targeting of IL-13 to the adult lung causes matrix metalloproteinase- and cathepsin-dependent emphysema. J Clin Invest 2000; 106: 1081-1093.

35 Choe KH, Taraseviciene-Stewart L, Scerbavicius R, et al. Methylprednisolone causes matrix metalloproteinase-dependent emphysema in adult rats. Am J Respir Crit Care Med 2003; 167: 1516-1521.

36 Taraseviciene-Stewart L, Scerbavicius $\mathrm{R}$, Choe $\mathrm{KH}$, et al. An animal model of autoimmune emphysema. Am J Respir Crit Care Med 2005 171: 734-742.

37 Lappalainen U, Whitsett JA, Wert SE, et al. Interleukin-1 $\beta$ causes pulmonary inflammation, emphysema, and airway remodeling in the adult murine lung. Am J Respir Cell Mol Biol 2005; 32: 311-318.

38 Russell RE, Culpitt SV, DeMatos C, et al. Release and activity of matrix metalloproteinase-9 and tissue inhibitor of metalloproteinase-1 by alveolar macrophages from patients with chronic obstructive pulmonary disease. Am J Respir Cell Mol Biol 2002; 26: 602-609. 
39 Segura-Valdez L, Pardo A, Gaxiola M, et al. Upregulation of gelatinases $\mathrm{A}$ and $\mathrm{B}$, collagenases 1 and 2, and increased parenchymal cell death in COPD. Chest 2000; 117: 684-694.

40 Imai K, Dalal SS, Chen ES, et al. Human collagenase (matrix metalloproteinase-1) expression in the lungs of patients with emphysema. Am J Respir Crit Care Med 2001; 163: 786-791.

41 Shapiro SD, Senior RM. Matrix metalloproteinases. Matrix degradation and more. Am J Respir Cell Mol Biol 1999; 20: 11001102.

42 Crapo JD, Barry BE, Gehr P, et al. Cell number and cell characteristics of the normal human lung. Am Rev Respir Dis 1982; 126: 332-337.

43 Lee JH, Lee DS, Kim EK, et al. Simvastatin inhibits cigarette smoking-induced emphysema and pulmonary hypertension in rat lungs. Am J Respir Crit Care Med 2005; 172: 987-993.
44 Takahashi S, Nakamura H, Furuuchi M. Simvastatin suppresses the development of elastase-induced emphysema in mice (abstract). Proc Am Thor Soc 2005; 2: A135.

45 Watts KL, Spiteri MA. Connective tissue growth factor expression and induction by transforming growth factor- $\beta$ is abrogated by simvastatin via a Rho signaling mechanism. Am J Physiol Lung Cell Mol Physiol 2004; 287: L1323-L1332.

46 Takeda N, Kondo M, Ito S, et al. Role of RhoA inactivation in reduced cell proliferation of human airway smooth muscle by simvastatin. Am J Respir Cell Mol Biol 2006; 35: 722 729.

47 Bell E, Ivarsson B, Merrill C. Production of a tissue-like structure by contraction of collagen lattices by human fibroblasts of different proliferative potential in vitro. Proc Natl Acad Sci USA 1979; 76: 1274-1278. 